\title{
Design and Simulation of Air-Fuel Percentage Sensors in Drone Engine Controlling
}

\author{
Mohammed Abdulla Abdulsada*, Mohammed Wajeeh Hussein, \\ Jabbar Shatti Jahlool and Majid S. Naghmash
}

Department of Computer Techniques Engineering, Dijlah University College, Baghdad, Iraq

('Corresponding author's e-mail: mohammed.abdulla@duc.edu.iq)

Received: 8 August 2020, Revised: 5 August 2021, Accepted: 8 August 2021

\begin{abstract}
This paper presents the design and simulation of air-fuel percentage sensors in drone engine control using Matlab. The applications of sensor engineering system have been pioneer in technology development and advancement of automated machine as complex systems. The integration of drone fuel sensor system is the major series components such as injector, pumps and switches. The suggested model is tuned to interface drone fuel system with fuel flow in order to optimize efficient monitoring. The sensor system is improved and virtualized in Simulink block set by varying the parameters with high range to observe the fuel utilization curves and extract the validated results. The obtained results show that the possibility of engine operation in critical conditions such as takeoff, landing, sharp maneuver and performance is applicable to turn off the system in case of break down in the sensor to ensure the safety of drone engine.
\end{abstract}

Keywords: Drone engine, Air-to-fuel ratio, Sensor fault, Matlab/Simulink

\section{Introduction}

In modern technology, the fast progression is vital factor for economic importance and development. The adoption and development of various strategies and technologies capacity is the major challenges to improve the welfare and operation requirements of drone in the industry of aerospace confronting $[1,2]$. The organizations of drone are in continuous condition of development as advanced in employed to monitor, control, operating and optimization of drone performances $[3,4]$. The drone design is complex to many automated systems which required carrying out the preferred functions [5-10]. Though, these technology adoptions are referred to flight control sensing system which is integrated to optimize the efficiency and performance maximization of drone behavioral $[11,12]$. The fuel sensor system of drone ensures the safety of return back in case of losing the path or anti-attack effects [13]. The most important is to know that the vital advantage of drone control sensor is to reduce the excess on auto pilot regarding to decision making which might lead to flight handle error $[14,15]$. The combustion engines include 2 types in drone designs, one is external combustion and the other is internal [16,17]. In first type, the combustion occurs outside the engine and the other is the power unconfined by flaming or oxidizing the fuel contained by the engine [18]. The internal burning engine purpose is to product the mechanical power from chemical energy.

The measurement of engine fuel by sensor system treated as the most important part in control operation [19]. The wideband air-fuel sensor of modern engine is vastly equipped to replace the conventional sensor that creates binary sequence for the air-to-fuel ratio [20,21]. The air-to-fuel ratio in the drone engine represents a primary dependent factor to reduce emissions and produce high torque with high efficiency. The air-to-fuel ratio should be maintained at stoichiometric value in the range of (14.5 14.7) to provide satisfactory operation condition [22]. When the air-to-fuel ratio increases above the stoichiometric value that needed for engine combustion, the result is the extraction of useful heat energy and system efficiency are reduced. The ability of the drone engine to operate under sensor fault conditions is called fault tolerant control system and considered as essential system in ensuring the safety and reliability.

Several controllers and techniques have been proposed for air-to-fuel ratio and fault tolerant control system. Cavina et. al. [23] proposed a closed-loop individual cylinder air-to-fuel ratio control using 
UEGO signal spectral analysis that controller is able to reduce cylinder air-to-fuel ratio inequality below 0.01 lambda. Postma and Nagamune [24] use a switching linear parameter varying (LPV) controller to regulate the air-to-fuel ratio. Simulations show the improved air-to-fuel ratio regulation of the switching LPV controller over the engine's operating range compared to that of an Hळo controller which is scheduled based on air flow only as well as a non-switching LPV controller. Yang et. al. [25] proposed a discrete-time dynamic model to represent the cyclic transient characteristics of the air-fuel mass with consideration of residual gas variation. In absence of lambda sensor, Kumar and Shen [26] present a model-based estimation and feedback control for cyclic air-to-fuel ratio of spark-ignition engines. Na et al. [27] proposed an alternative control to maintain the air-to-fuel ratio at stoichiometric value based on a mean-value engine model (MVEM) with satisfactory transient and steady-state performance. A new airfuel ratio control method based on fuzzy-PID is proposed by Wang et al. [28]. In normal condition, the air-to-fuel ratio control error was reduced by $80 \%$ compared with PID control. According to the optimum fuel injection results, a fuzzy-PID method is presented to control the air-to-fuel -ratio in different situations that shorten the time response of the engine speed by $2 \mathrm{~s}$, improve the power efficiency to $33 \%$ and improve the endurance by $30 \mathrm{~min}$ with a normal engine speed. A hybrid faults tolerant control system for air-to-fuel ratio control based on Kalman filters and triple modular redundancy is presented by Amin and Mahmood-Ul-Hasan [29]. The study presents a novel and highly reliable solution for the air-to-fuel ratio control in internal combustion engines to prevent engine shutdown and production loss for greater profits. Gianfranco Gagliardi et al. [30] proposed a hybrid observer scheme which employed in a PI control loop designed to maintain the air-to-fuel ratio close to a required value. The effectiveness of the proposed scheme is demonstrated by several numerical simulations based on both synthetic and real data.

Figure 1 shows the flow chart of time sequence which demonstrates the module and process of the fault tolerant system suggested by [22]. At normal operating, the fault tolerant module supplies the desired air-to-fuel ratio for feedback controller. When an air-fuel sensor fault is detected, a correction signal will be sent to the controller.

In this work, the management of fault tolerant requirements for drone engine is proposed and modeled using Matlab Simulink block set. The designed model is build and examine under different effects to show the suggested algorithms performance.

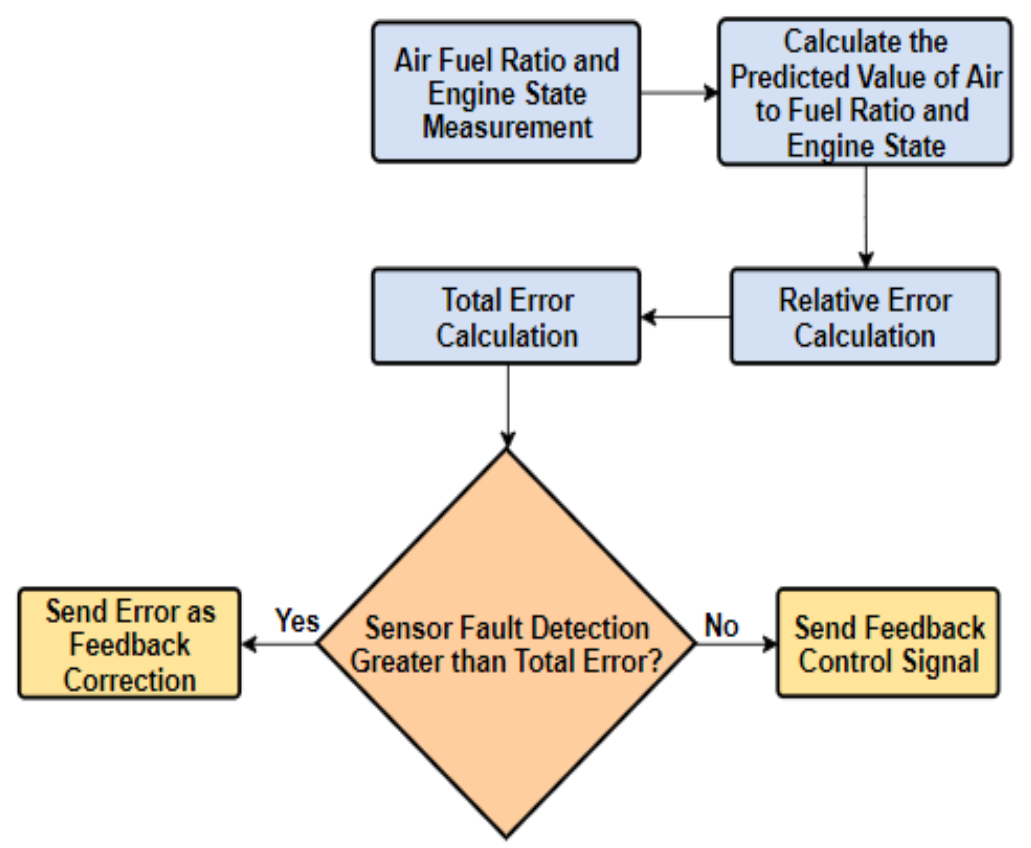

Figure 1 Fault tolerant module flow chart operation. 


\section{Materials and methods}

Figure 2 shows the fault tolerant fuel sensor system which has been designed and running in Matlab. The requirements of drone engine are managing according to safety condition. The top level controller uses signals from the sensor to determine the fuel rate to produce the mixture of stoichiometric ratio. The combined fuel rate with actual air flow inside the engine to calculate the resulting mixing ratio as sensed at drain. To disable every sensor, one could select speed, EGO, throttle angle and manifold absolute pressure in order to simulate the failures state. In same time one could induce the malfunction state of high speed by toggling the switch on the far left. The table block could be repeating to provide the angle of throttle input and occasionally repeats the sequence of data particular in the facade.

Figure 3 illustrates the dynamic model of drone engine sensor for air-to-fuel ratio. Figure 4 shows the selected improvement loop and filtering model features of proposed design. The air flow of in tank estimation close loop is used to correct the error by calculate the permit ration tolerant as shows in Figure 5.

The subsystem of throttle and intake manifold model behaves in nonlinear principle with 3 inputs to provide convenient methods and describing the equation of many variables. To determine whether the flow is sonic, the switch block is used by comparing the ratio of pressure with threshold which is set as one half. The flow rate in sonic regime is a function of the position of throttle and the direction of flow from higher to lower pressure. The mine block ensures the pressure ration which is less or equal to one.

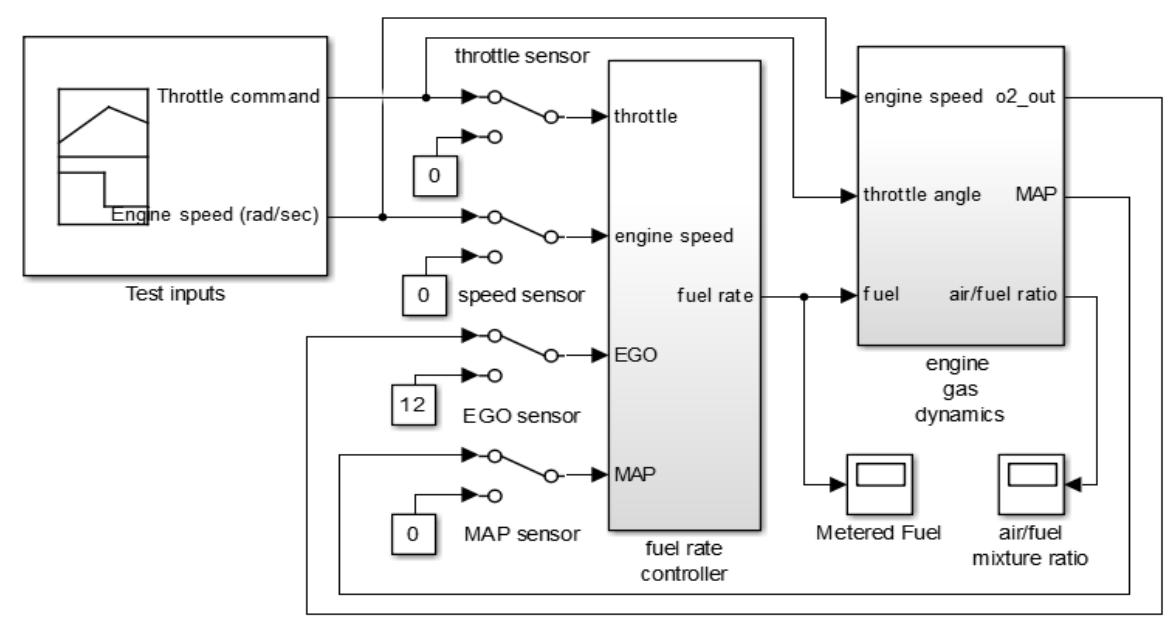

Figure 2 Fault sensor system of drone engine air to fuel ratio model.

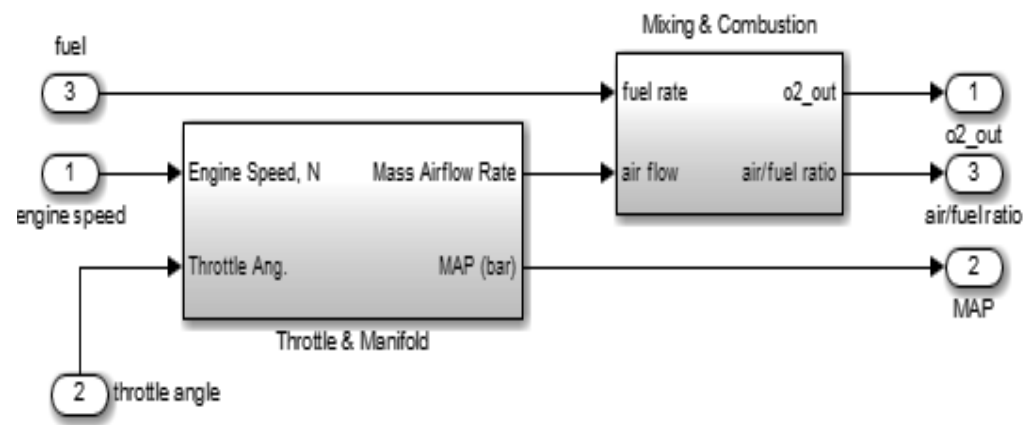

Figure 3 The dynamic model of drone engine. 


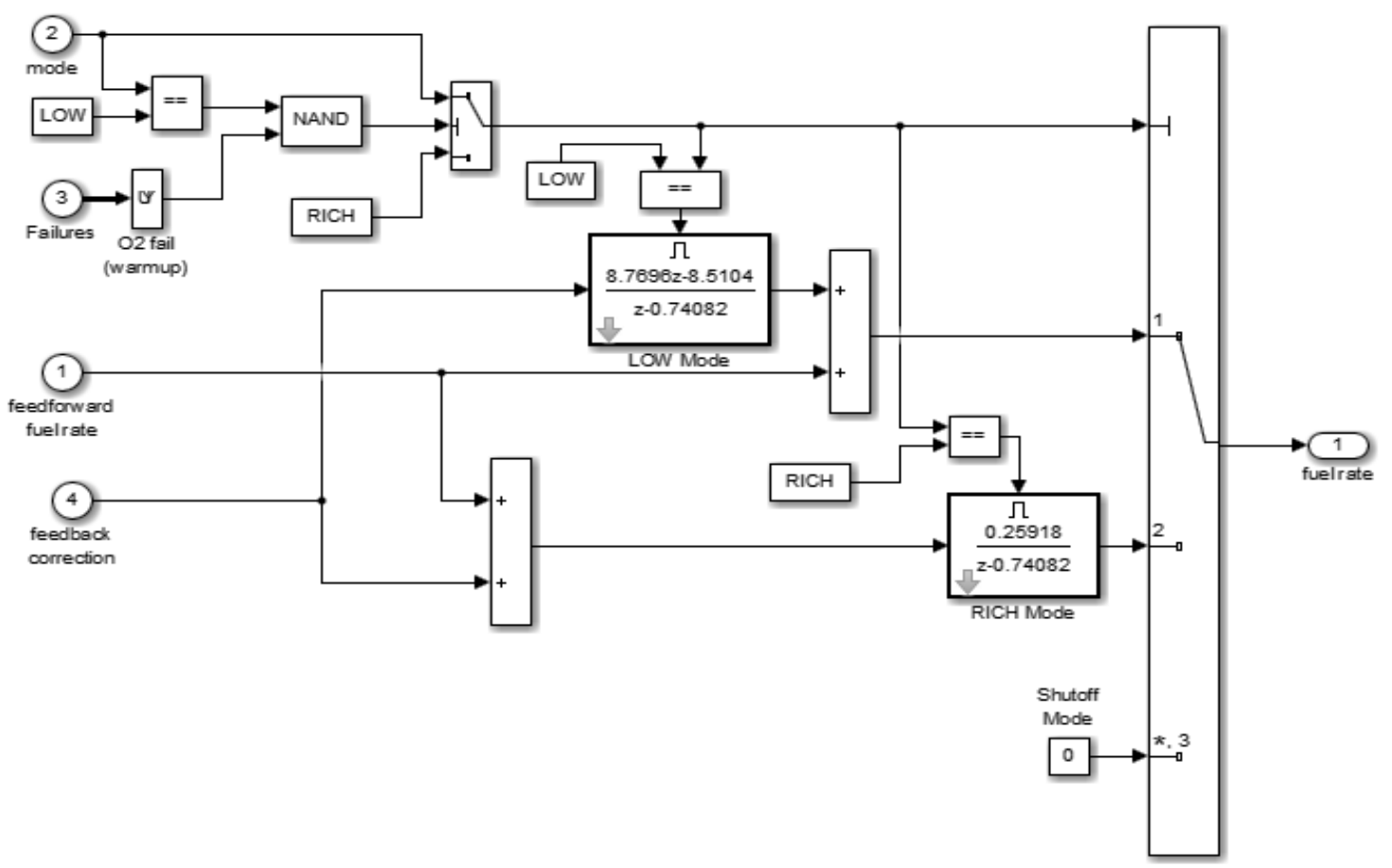

Figure 4 Improvement loop and filtering model features.

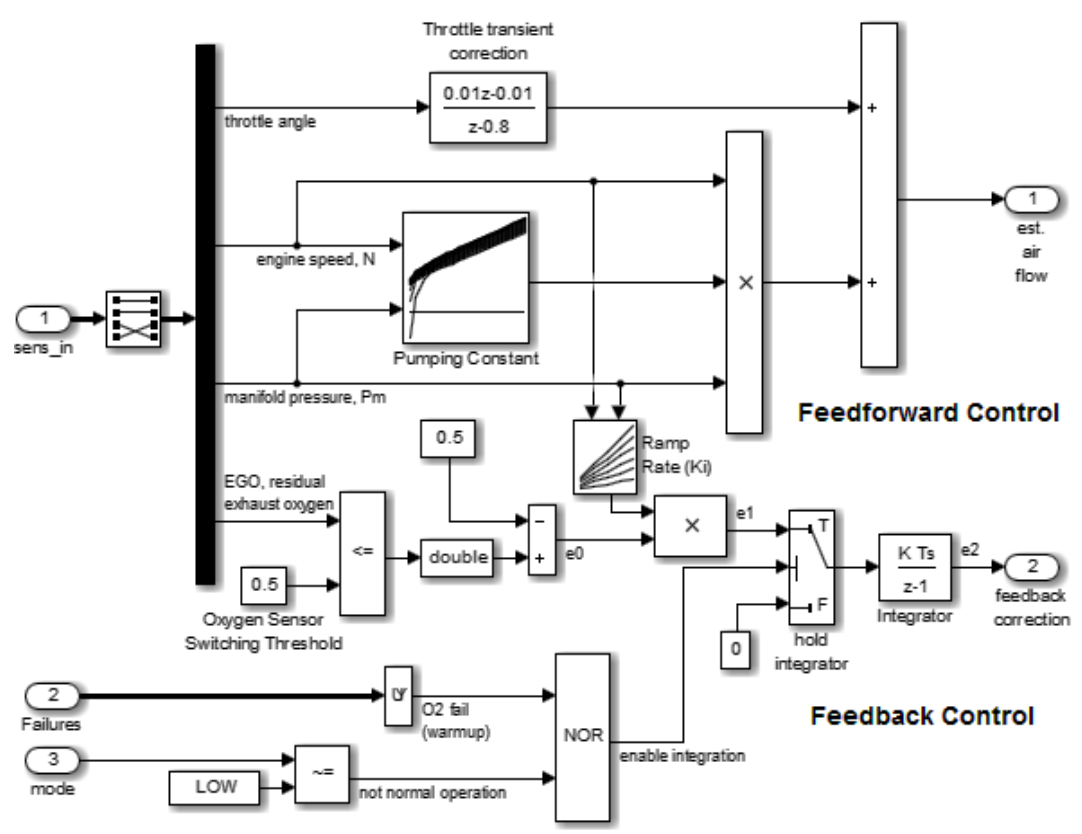

Figure 5 The air flow of in tank estimation close loop.

Figure 6 shows the fault correction block subsystems which are used to determine which sensor could be used and which sensor could estimate. The input of failures is the vector of logic signals which trigger the estimation application to every sensor. In case of a signal component is 0 , the estimation system is enabled the appropriate estimate and cause the switch relating to signal and send this estimation to the output. The estimation routines dose not introduce any computational overhead since it's within enable conditions in case of not wanted. The input of sensors to the correction part is a vector of raw sensor and in case of no faults, the input simply pass on. In case of the fault is existing, the estimation block is use this signal to recover the component missing from the sensor. 


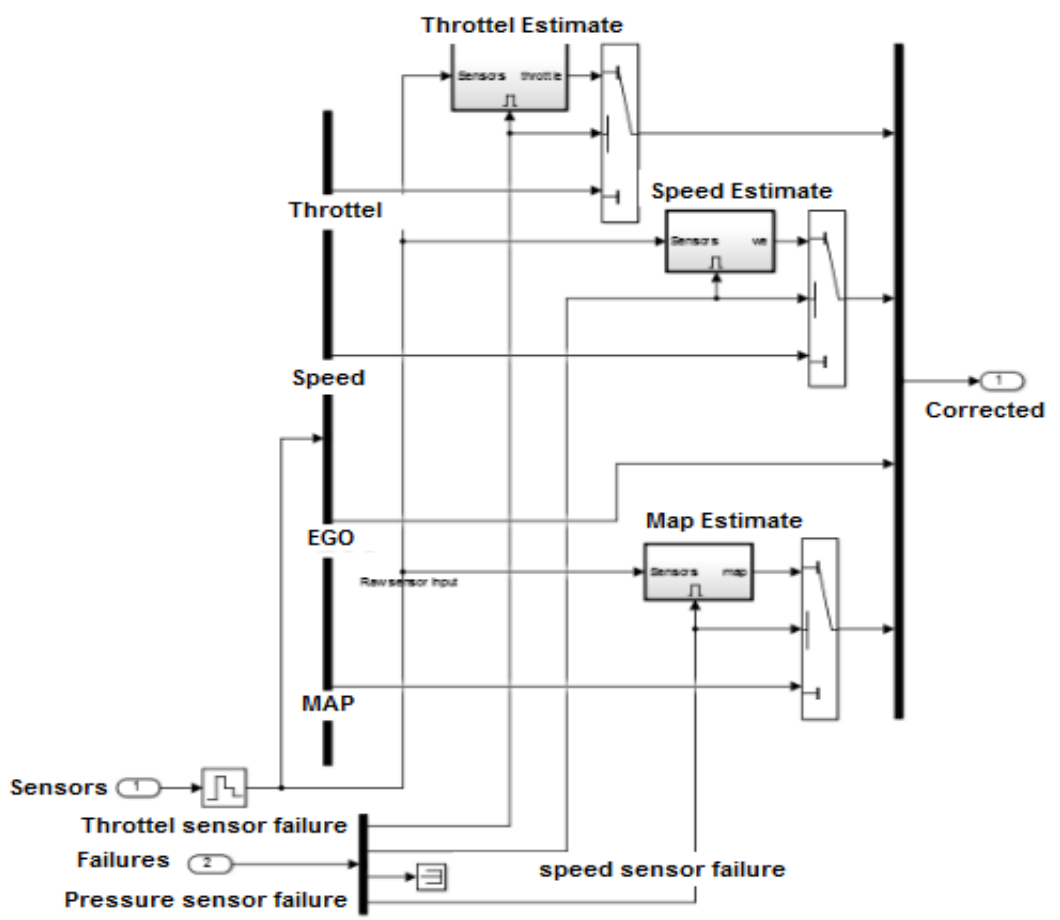

Figure 6 Sensor correction and fault redundancy model.

Figure 7 shows controller of sensor input and feedback signal to adjust the fuel rate to provide the ration of stoichiometric. Four subsystems are included in this model to implement the control logic, air flow calculation, sensor correction strategies. In case of normal operations, the model estimates the air flow rate and multiplies by reciprocal preferred ratio to provide fuel rate. From the oxygen sensor feedback produce close loop adjustment of estimated rate to keep the ideal ration of mixture.

Figure 8 shows the subsystem of fuel calculation which is set to inject the signal to match with given air flow determination and the status of faults. The determined air flow estimation is achieved by first input to this subsystem and multiplied by targeted ratio of fuel to air which provide a command of fuel rate of about 1/14.6. In case of sensor fault happened, the state flow control the logic set the input mode to 2 or 3 , hence, the mixture is moreover somewhat rich of stoichiometric or shut down totally.

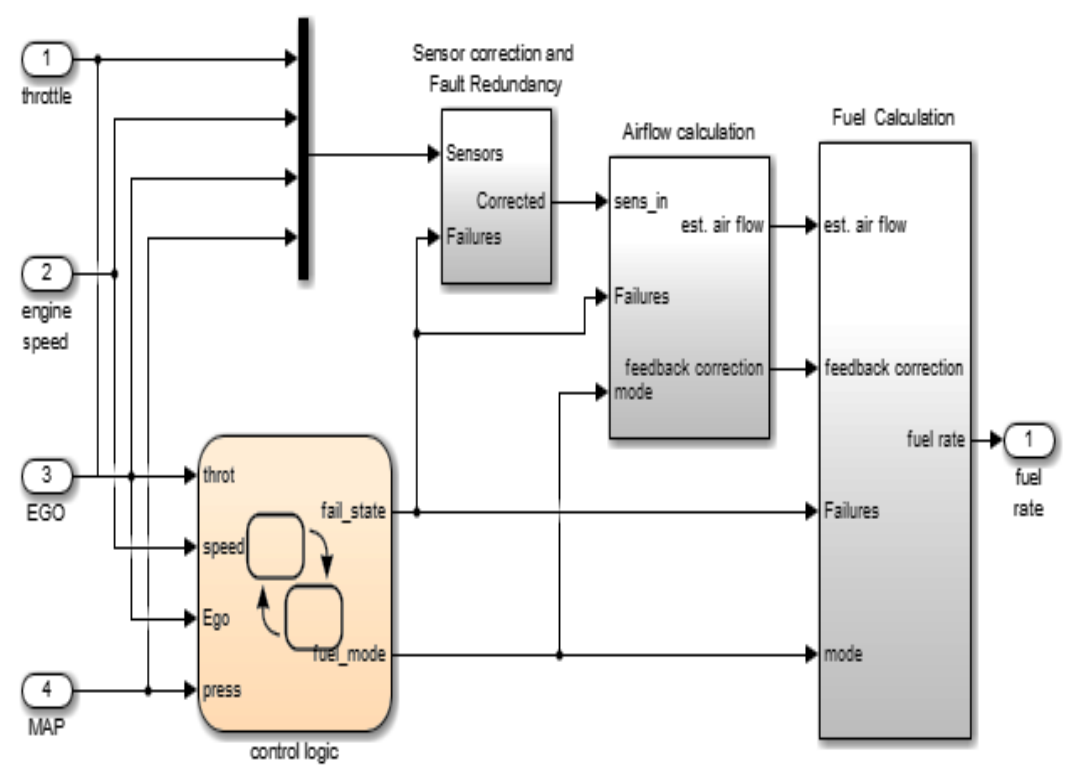

Figure 7 Fuel rate controller model. 


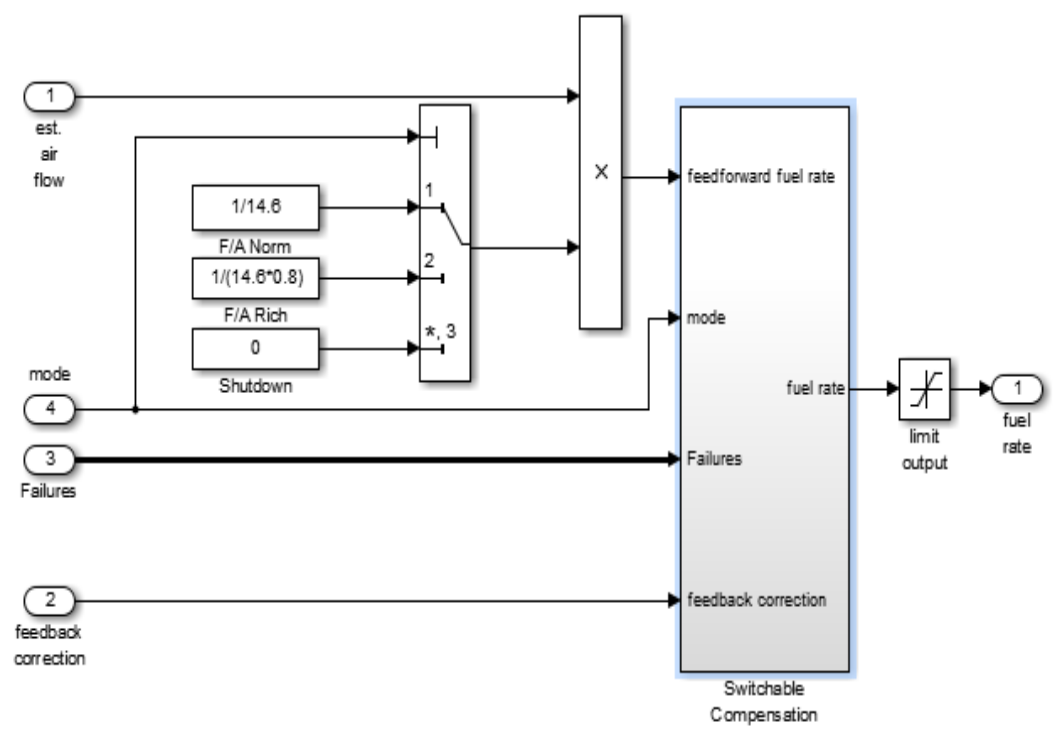

Figure 8 Fuel rate calculation model.

\section{Results and discussion}

Figure 9 illustrates the simulation results of suggested model which is running with throttle input of 10 to $20^{\circ}$ over duration of $2 \mathrm{~s}$ and return to $10^{\circ}$ over next $2 \mathrm{~s}$. This duration is repeated incessantly whilst the engine is detained at steady speed. Hence, the experiment could use with different failure mode and fault considerations. The corresponding air-to-fuel ratio for every cycle showing by plot scope exhibit the effect of close loop operation with mixture ratio of 14.6 which represents the regular tight to objectives of stoichiometric.

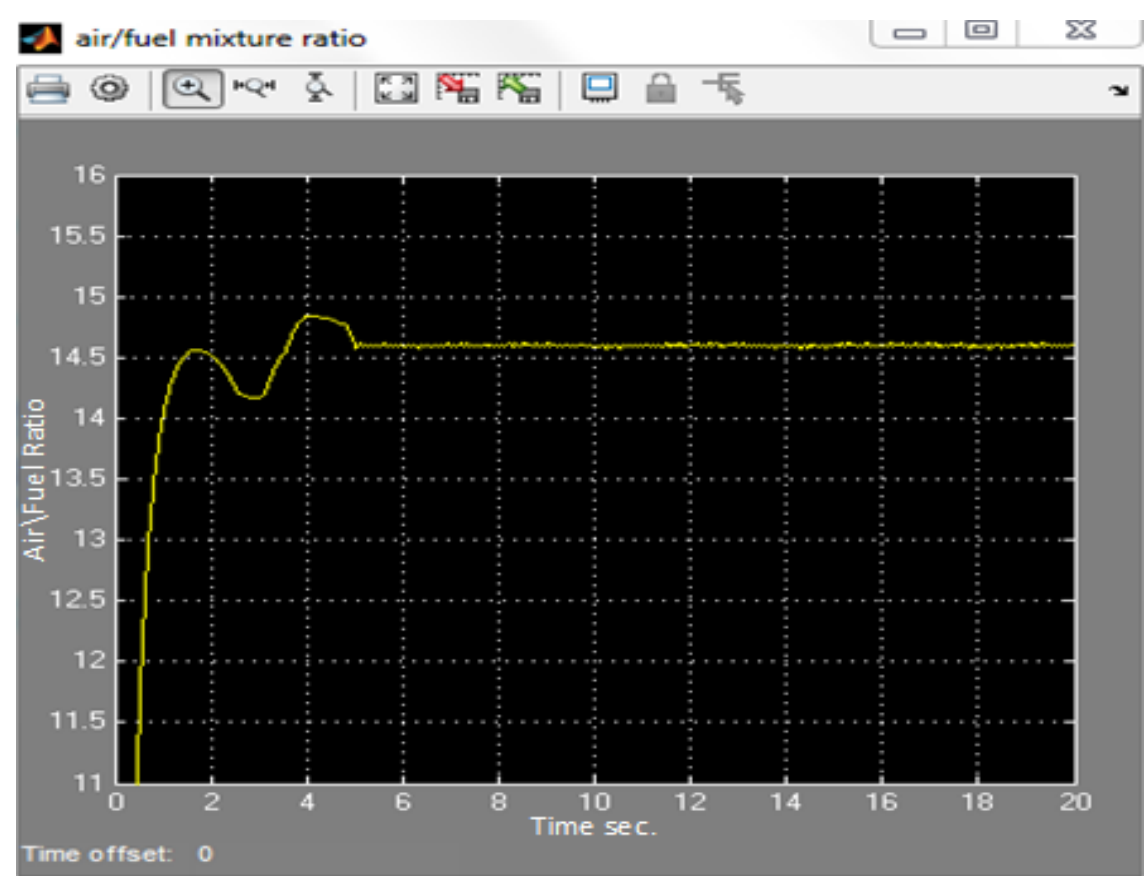

Figure 9 Simulated results of air-to-fuel ratio. 
Figure 10 shows the fuel flow rate under fault free situation with practical rate in occurrence of signal failure in every sensor. The nonlinear relation between fuel flow and the triangular throttle command is memorandum in each case. The fuel flow rate is regulated tightly in the baseline with small ripple because of switching nature of sensor input. The operation of system is open loop in the other cases and the control strategy is proven in keeping the correct fuel profile in the single failure stage which is fulfill the goal of this design.

Some limitations of this work are explained below; drone.

1) The real time test in the experimental locations not permits to do all parameters checking of

2) Some parts of the drone used in field experiments, especially the sensors, are inefficient as a result of their unavailability in our country.

The drone structures parameters need to be inserted in this work such as drone weight control and drone structure materials which will effect on the results.

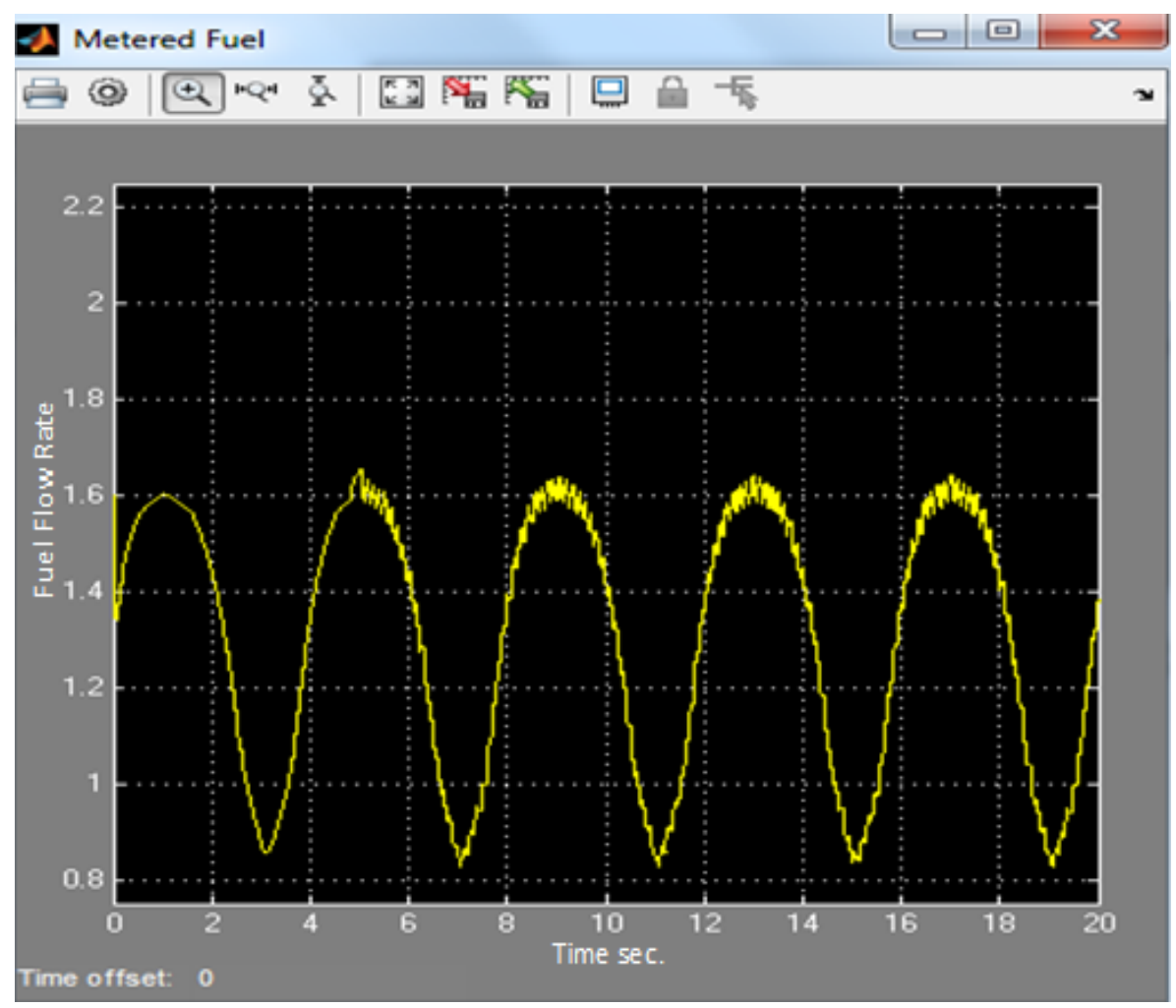

Figure 10 Fuel flow rate under fault free situation.

\section{Conclusions}

In this paper, the drone engine fuel rate sensor is designed and examined under different effects to determine the air-to-fuel ratio system. This model involves sequence of interconnection among various parts of fuel system design. Thought, the design goals could be used as resource to treatment the operation quality in percentage. Additional approach is required by using more sensors and investigation could be carry out in the fuel control sensing between tanks of drone which could enable more approaches to improve the vital specifications in designing of fuel system with more varying range of parameters in case of break down the engine. In order to optimize the drone aerodynamic, the concept of fuel consuming at the reservoir are out of board earlier than using the in board container. This is significantly developed the stability and prevent unprecedented drone controlling. The simulation results illustrate the feeler fault could be festally notice by fault to broadminded design providing exact time. The engine operation is changes after establishing the sensor fault into the tank engine scheme to set the strength of organize method. The control structure of the proposed design is found to be simple, efficient and provides the required air-to-fuel ratio performance at the stoichiometric value for the drone engine operation. 


\section{References}

[1] MJ Boyle. The drone age. Oxford University Press, New York, 2020.

[2] F Al-Turjman. Drones in smart-cities: Security and performance. Elsevier, Amsterdam, Netherlands, 2020.

[3] AA Najm and IK Ibraheem. Altitude and attitude stabilization of UAV quadrotor system using improved active disturbance rejection control. Arabian J. Sci. Eng. 2020; 45, 1985-99.

[4] M Mozaffari, W Sadd, M Bennis and M Debbah. Communications and control for wireless dronebased antenna array. IEEE Trans. Comm. 2019; 67, 820-34.

[5] Ş Yıldırım, N Çabuk and V Bakırcıoğlu. Design and trajectory control of universal drone system. Measurement. 2019; 147, 106834.

[6] P Sanjana and M Prathilothamai. Drone design for first aid kit delivery in emergency situation. In: Proceedings of the $6^{\text {th }}$ International Conference on Advanced Computing and Communication Systems, Coimbatore, India. 2020, p. 215-220.

[7] AA Najm, IK Ibraheem, AJ Humaidi and AT Azar. Output tracking and feedback stabilization for 6-DoF UAV using an enhanced active disturbance rejection control. Int. J. Intell. Unmanned Syst. $2021 ; 3,1-16$.

[8] N Mahamud, GM Shahriar, HU Khan, S Sharmin and NJ Lisa. ALW drone: A new design and efficient approach. In: Proceedings of the $19^{\text {th }}$ International Conference on Computer and Information Technology, Dhaka, Bangladesh. 2016, p. 474-479.

[9] M Hell, RC Bolam and Y Vagapov and A Anuchin. Design of a portable drone for educational purposes. In: Proceedings of the $25^{\text {th }}$ International Workshop on Electric Drives: Optimization in Control of Electric Drives, Moscow, Russia. 2018.

[10] HK Pitchiah and AAM Moshi. Design and analysis of roto - cylindrical wing for a drone aircraft. Mater. Today Proc. 2020; 22, 393-9.

[11] AA Najm and IK Ibraheem. Nonlinear PID controller design for a 6-DOF UAV quadrotor system. Eng. Sci. Tech. Int. J. 2019; 22, 1087-97.

[12] AY Husodo, G Jati, A Octavian and W Jatmiko. Switching target communication strategy for optimizing multiple pursuer drones performance in immobilizing Kamikaze multiple evader drones. ICT Express. 2020; 6, 76-82.

[13] Y Shi, DL Yu, Y Tian and Y Shi. Air fuel ratio prediction and NMPC for SI engines with modified volterra model and RBF network. Eng. Appl. Artif. Intell. 2015; 45, 313-24.

[14] S Roy, R Banerjee, AK Das and PK Bose. Development of an ANN based system identification tool to estimate the performance-emission characteristics of a CRDI assisted CNG dual fuel diesel engine. J. Nat. Gas Sci. Eng. 2014; 21, 147-58.

[15] S Kouroshnezhad, A Peiravi, MS Haghighi and A Jolfaei. An energy-aware drone trajectory planning scheme for terrestrial sensors localization. Comput. Comm. 2020; 154, 542-50.

[16] J Huber, H Kopecek and M Hofbaur. Nonlinear model predictive control of an internal combustion engine exposed to measured disturbances. Contr. Eng. Pract. 2015; 44, 78-88.

[17] D Cawthorne and A Cenci. Value sensitive design of a humanitarian cargo drone. In: Proceedings of the International Conference on Unmanned Aircraft Systems, Atlanta, GA, USA. 2019, p. 1117-25.

[18] Z Chuntang and W Shaokun. System design for aircraft fuel control and maintenance test-bed. In: Proceedings of the $26^{\text {th }}$ Chinese Control and Decision Conference, Changsha, China. 2014, p. 347881.

[19] DK Srivastava, AK Agarwal, A Datta and RK Maury. Advances in internal combustion engine research. Springer, Singapore, 2018.

[20] B Ebrahimia, R Tafreshi, H Masudi, M Franchek, J Mohammadpour and K Grigoriadis. A parameter-varying filtered PID strategy for air-fuel ratio control of spark ignition engines. Contr. Eng. Pract. 2012; 20, 805-15.

[21] SA Ali, M Guermouche and N Langlois. Fault-tolerant control based super-twisting algorithm for the diesel engine air path subject to loss-of-effectiveness and additive actuator faults. Appl. Math. Model. 2015; 39, 4309-29.

[22] YJ Zhai, DL Yu, KJ Qian, S Lee and N Theera-Umpon. A soft sensor-based fault-tolerant control on the air fuel ratio of spark-ignition engines. Energies 2017; 10, 131.

[23] N Cavina, E Corti and D Moro. Closed-loop individual cylinder air-fuel ratio control via UEGO signal spectral analysis. Control Eng. Pract. 2010; 18, 1295-306. 
[24] M Postma and R Nagamune. Air-fuel ratio control of spark ignition engines using a switching LPV controller. IEEE Trans. Contr. Syst. Tech. 2012; 20, 1175-87.

[25] J Yang, T Shen and X Jiao. Stochastic adaptive air-fuel ratio control of spark ignition engines. IEEJ Trans. Electr. Electron. Eng. 2014; 9, 442-7.

[26] M Kumar and T Shen. Estimation and feedback control of air-fuel ratio for gasoline engines. Contr. Theor. Tech. 2015; 13, 151-9.

[27] J Na, G Herrmann, C Rames, R Burke and C Brace. Air-fuel-ratio control of engine system with unknown input observer. In: Proceedings of the 2016 UKACC $11^{\text {th }}$ International Conference on Control, Belfast, UK. 2016.

[28] W Yixuan, S Yan, C Maolin, X Weiqing and Y Qihui. Optimization of air-fuel ratio control of fuelpowered UAV engine using adaptive fuzzy-PID. J. Franklin Inst. 2018; 355, 8554-75.

[29] AA Amin and K Mahmood-Ul-Hasan. Hybrid fault tolerant control for air-fuel ratio control of internal combustion gasoline engine using Kalman filters with advanced redundancy. Meas. Contr. 2019; 52, 473-92.

[30] G Gagliardi, D Mari, F Tedesco and A Casavola. An air-to-fuel ratio estimation strategy for turbocharged spark-ignition engines based on sparse binary HEGO sensor measures and hybrid linear observers. Contr. Eng. Pract. 2021; 107, 104694. 